\title{
Estudo exploratório sobre aplicativos de realidade aumentada direcionados para a aprendizagem Matemática
}

\author{
Bruno Resende \\ Pontifícia Universidade Católica do Rio Grande do Sul (PUCRS) \\ (bruno.resende@acad.pucrs.br) \\ Isabel Cristina Machado de Lara \\ Pontifícia Universidade Católica do Rio Grande do Sul (PUCRS) \\ (isabel.lara@pucrs.br)
}

\begin{abstract}
Resumo: O presente artigo busca proporcionar uma visão geral sobre o que se encontra de aplicativos disponíveis na plataforma Android para dispositivos móveis no âmbito da Realidade Aumentada (RA) cujo objetivo é contribuir para a aprendizagem matemática. Para isso, adota-se a pesquisa exploratória como procedimento metodológico no intuito de identificar os aplicativos presentes na loja virtual Google Play com enfoque na experiência e interação visual/espacial da tecnologia com matemática. Os resultados tornaram possível reconhecer que são poucos os aplicativos existentes que preocupam-se com os processos de aprendizagem matemática no campo da RA. Além disso, nota-se que os aplicativos encontrados não apresentam um número considerável de avaliações e comentários acerca de seu desempenho. Entretanto, compreende-se que persistir no desenvolvimento de aplicativos em RA explorando conteúdos matemáticos é aumentar as possibilidades de inovar no campo educacional matemático.
\end{abstract}

Palavras-chave: Realidade Aumentada; Tecnologia; Matemática; Dispositivos Móveis.

\section{Exploratory study on augmented reality applications leaded for mathematical learning}

Abstract: This article aims to provide an overview of what is available on the Android platform for mobile devices in the framework of Augmented Reality (RA) whose goal is to contribute to mathematical learning. For this, an exploratory research was adopted as a methodological procedure in order to identify the existing applications in the Google Play virtual store, focusing on the experience and visual/spatial interaction of technology and mathematics. The results made it possible to observe the reduced available existing applications concerned about the mathematical learning processes in the RA field. Furthermore, it is noted that the applications found do not present a considerable number of evaluations and comments regarding their performance. However, it is understood that persisting in the development of applications in RA exploring mathematical contents will increase the possibilities of innovations in the mathematical educational field.

Keywords: Augmented Reality; Technology; Math; Mobile Devices. 


\section{INTRODUÇÃO}

$\mathrm{Na}$ organização de um mundo cada vez mais digital e virtual, inovações são criadas e desenvolvidas de um modo que provoquem efeitos na evolução humana. O progresso da ciência e tecnologia tem proporcionado grandes avanços em diversas áreas do conhecimento e alterações nas relações/valores sociais visto que "[...] ciência e tecnologia constroem o motor que aciona o mundo moderno." (SERGE et. al., 2004).

A modernidade constitui um vínculo intrínseco entre o modo de pensar e o desenvolvimento tecnológico (SCHOR, 2008), pois, caracterizou-se, conforme Rodrigues pela racionalidade, mecanização e "[...] difusão de informações de forma rápida e eficaz [...]" (2012, p. 121). Diante desse contexto, a tecnologia, que está na vivência do homem e subjetiva o seu modo de conviver com o mundo (MELGAÇO et. al., 2017) traz consequências para a realidade da vida cotidiana.

Neste artigo, partindo-se da ideia de que: "A tecnologia tem vindo continuamente a alterar de forma profunda de como as pessoas aprendem e vivem." (CRUZ-CUNHA et al., 2010, p.167), buscou-se apresentar uma investigação sobre o cenário dos aplicativos existentes para a aprendizagem matemática na esfera da Realidade Aumentada, além das considerações dos usuários sobre as aplicações melhores avaliadas na loja virtual da plataforma Android. Para tanto, realizou-se uma pesquisa sobre embasamentos teóricos em relação à realidade, matemática e tecnologia.

\section{REALIDADE, MATEMÁTICA E TECNOLOGIA}

Segundo Berger e Luckmann (2004, p.38), "[...] o mundo consiste em múltiplas realidades.". Dentre as muitas realidades, existe uma que é considerada como realidade por excelência: a do "aqui" e "agora". "Aquilo que é 'aqui' e 'agora' apresentado [...] é a zona da vida cotidiana diretamente acessível à minha manipulação corporal." (BERGER; LUCKMANN, 2004, p. 39). Sendo assim, os autores definem que a realidade é a interpretação dos seres humanos da vida cotidiana e subjetivamente composta de significados na medida em que forma um mundo coerente para as suas vivências. 
Além da realidade, que é inerente à vida, a Matemática está presente em toda parte. É uma ciência que "[...] está presente em toda a natureza, na arte e no mundo [...]." (BOALER, 2016, p.26). Adicionado a isso, Portanova (2005) afirma que a Matemática é a base do conhecimento científico, tecnológico e sociológico, em vista que, na história da humanidade as ideias matemáticas estão presentes nas maneiras de fazer e de saber. Assim, compreende-se que a matemática faz parte das ações humanas no que diz respeito à interpretação da realidade ao redor do homem. Mais do que sustentação do conhecimento científico (cálculos e porções de números), a matemática, que desde os primórdios serviu para auxiliar nas atividades e organizar a sociedade, é vista como intrínseca no contexto social em razão de que é necessária para as relações interpessoais (CONCEIÇÃO; ALMEIDA, 2015).

A respeito da relação social, a realidade é partilhada entre os seres humanos durante as ações da vida cotidiana. Desse modo, a prática mais importante na interação social acontece na circunstância de estar face a face com o outro. Nessa situação, "Meu 'aqui e agora' colidem continuamente um com o outro enquanto dura a situação face a face." (BERGER; LUCKMANN, 2004, p. 47). Complementando isso, os autores descrevem que nenhuma outra forma de interação pode expressar a plenitude do contexto frente a frente que é "próxima". Quaisquer outros modos de relação com o outro são "variáveis" e não representam a integridade (valor/perfeição) que a situação "cara a cara" proporciona. Isto é, a relação face a face é a experiência mais significativa e marcante na inter-relação. Assim, trata-se de uma correspondência mútua partilhada por dois indivíduos em uma reciprocidade de atos. "Na situação face a face o outro é plenamente real. Essa realidade é parte da realidade global da vida cotidiana, e como tal maciça e irresistível." (BERGER; LUCKMANN, 2004, p. 47).

Em paralelo a isso, tem-se a aparição de novas dimensões de realidade no cenário tecnológico como o surgimento e a utilização de dispositivos móveis na vida humana. Com a popularização e a integração desses recursos com diversas plataformas, a sociedade está mais dependente desses instrumentos tecnológicos e, de acordo com Serge et al (2004), com medo de não conseguir viver sem eles. Além disso, a relação entre os indivíduos "[...] estão saindo, com frequência, da esfera face a face para se tornarem virtuais. Estamos nos ambientando a classificar a realidade da vida cotidiana também por meio das relações que estabelecemos com 
as pessoas pela internet e pelo celular multiplataformas [...]." (JÚNIOR; SIQUEIRA; ROCHA, 2013, p. 6). Coutinho (2014) aponta como um exemplo disso o grande crescimento de dispositivos portáteis no cenário mundial que chegam a superar o número de 7 bilhões $^{1}$ de aparelhos. Não são somente os números que chamam a atenção, mas a qualidade e rapidez que a tecnologia evoluiu, pois, esses aparelhos possuem capacidade de processamento superior que muitos computadores de antigas gerações (COUTINHO, 2014).

Além desses números sobre produção mundial de dispositivos móveis ao redor do mundo, segundo dados da Anatel, só no Brasil, no mês de julho de 2017, foram registrados 242 milhões $^{2}$ de celulares. Desse modo, entende-se que a realidade da dimensão tecnológica dos mobiles (smartphone e tablets) possui uma gama de aplicativos para essas plataformas. Com as crescentes novidades de aplicações nesse campo, destacam-se os impactos significantes das plataformas digitais na vida humana em várias áreas.

Segundo Barbosa, Roesler e Cazella (2016), os aplicativos para plataformas móveis estão se tornando cada vez mais importantes ferramentas e são usados para muitas finalidades como jogos, comunicação, entretenimento, saúde e na área da educação. As Tecnologias da Informação e Comunicação Móveis e Sem Fio (TIMS), além de servirem como recursos didáticos e pedagógicos que possibilitam a mobilidade, agregam desafios para a realidade escolar (BENTO; CAVALCANTE, 2013).

$\mathrm{Na}$ matemática, em particular, existem vários aplicativos e outros ainda em desenvolvimento voltados à aprendizagem dessa disciplina. Porém, muitos desses aplicativos necessitam ser avaliados porque não contêm funcionalidades e/ou características apropriadas (DA SILVA; BATISTA, 2015). Com novas dimensões de realidade na sociedade, na vida cotidiana e também na Educação Matemática, destacam-se as realidades Virtual e Aumentada. Essas representações virtuais são as mais recorrentes na área da Tecnologia da Informação quando se referem a recursos de exibições multimídia (DE SOUZA; GIGLIO, 2015). Por consequência, essas tecnologias têm um grande destaque quando o objetivo é a interação com

\footnotetext{
1 http://fabricadeaplicativos.com.br/inovacaoetecnologia/o-mundo-mobile/

2 http://www.teleco.com.br/ncel.asp
} 
projeções digitais no ambiente real e experiência sensorial, uma vez que possuem distinções entre si e características específicas. Assim, diferentemente da Realidade Virtual (RV), que algumas vezes precisa de equipamentos especiais de visualização sendo utilizados em ambientes particulares e reclusos, a RA não é exigente ao ponto de necessitar de recursos tão restritos em razão de poder ser inserida em qualquer atmosfera (KIRNER; SISCOUTTO, 2007).

\subsection{Realidade aumentada}

Nas palavras de Azuma (1997), a RA é definida como uma variação de um Ambiente Virtual (Virtual Environment) que projeta objetos sobrepostos em cima ou em composição com a realidade mundana suplementando-a ao invés de completamente substituí-la. O Ambiente Virtual, por sua vez, submerge o usuário no mundo virtual de modo que não consiga olhar para a realidade mundana.

Segundo Forte e Kirner (2009), a RA se refere à realidade mundana com um ponto inicial para uma tentativa de ensaio que leva o usuário a vivenciar um mundo virtual (sem sair dessa realidade). Assim, a RA não extrai o usuário da realidade mundana, mas utiliza o mesmo ambiente em que ele se encontra inserindo materiais tridimensionais em uma experiência que combina o mundano e o virtual. Sobretudo, a RA sobrepõe objetos em ambientes físicos por meio de um instrumento tecnológico (KIRNER; SISCOUTTO, 2007).

O avanço da tecnologia e as formas de investigações da RA contribuíram para o desenvolvimento de abordagens diferenciadas como a utilização de dispositivos móveis com RA, para ambientes educacionais. Para Marçal, Andrade e Rios (2005), isso ocorreu quando os recursos da computação gráfica móvel se manifestaram como uma tecnologia renovadora para a educação.

Assim, entende-se que ao inserir essas tecnologias, atividades e explorações com o mundo cibernético, interagindo com a realidade mundana na esfera educacional matemática, criam condições para criar outras possibilidades para a aprendizagem de matemática.

Aproveitar-se dos recursos da RA e aplicá-los na educação é uma forma de construir alternativas ao lado dos livros, fotos, ilustrações, vídeos e das aulas 
expositivas. Atividades com RA podem contribuir para um ambiente de conexão não só entre tecnologia e matemática, mas com outras áreas da educação ou ciência.

Nesse sentido, além de computadores pessoais, as tecnologias móveis estão presentes na sociedade e cada vez mais fazem parte das tarefas diárias dos usuários. Estão, assim, interferindo no modo como buscam informação, conhecimento, trabalho e viver. Tomando vantagem dos recursos móveis, buscou-se por aplicações de RA em aplicativos móveis sem preocupação em utilizar computadores pessoais, mas pensando em dispositivos que estão constantemente com os professores e alunos, como os smartphones, por exemplo. Possuir um aparelho com vários recursos e que as pessoas estão acostumadas a utilizá-los pode servir como um importante recurso da tecnologia para trabalhar em conjunto com a RA. Segundo Cruz-Cunha et. al. (2010) um dispositivo móvel é um meio de aprendizagem de grande valor.

Procurar maneiras diferentes de se refletir sobre atividades que envolvam a matemática para dentro de uma aplicação de RA é um desafio a ser superado. Criar, desenvolver, planejar e executar uma aplicação ou um aplicativo (para smartphone) com objetivo principal sendo a exploração de objetos ou cenários matemáticos seria fundamental e de grande benefício para a Educação Matemática. Como argumentam Cruz-Cunha et. al. (2010), algumas TIC trazem vantagens e podem beneficiar a educação e um bom campo para aplicar essas TIC seria a matemática.

A RA presente em softwares que interagem com o usuário por meio de sistemas de saída como monitores e projetores expressa com naturalidade objetos ou materiais virtuais em um ambiente da realidade mundana. Cuperschmid e Freitas (2013, p. 12) relatam isso quando dizem que "[...] a RA permite que usuários interajam com o conteúdo virtual de uma maneira natural, intuitiva.". Contudo, os aplicativos de RA para smartphones ficam abaixo do esperado não só para a área da matemática, mas como outras áreas como Arquitetura, Engenharia e construção (AEC) (CUPERSCHMID; FREITAS, 2013).

Entende-se que existe uma preocupação em conhecimentos técnicos para que se possa unir a tecnologia, a RA e a matemática devido às barreiras encontradas. Entretanto, compreende-se que persistir em um caminho que busque estudos para entender, explorar e alavancar as aplicações da RA é importantíssimo para a inovação na aprendizagem matemática. 
No contexto da tecnologia que faz parte das vivências cotidianas do ser humano e a realidade considerada por excelência a do "aqui" e "agora", surgiram indagações sobre o panorama dos dispositivos móveis na matemática. Questionamentos sobre a realidade do uso de aplicativos nos dispositivos móveis (smartphones e tablets) para a aprendizagem matemática, especificamente no âmbito da RA. Nessa perspectiva, desenvolveu-se uma investigação motivada por essas questões e com objetivo de tentar obter maior compreensão do tema estudado (do que existe sobre aplicativos de RA voltados para a aprendizagem matemática). Com isso, na próxima seção, apresenta-se o procedimento metodológico utilizado.

\section{PROCEDIMENTOS METODOLÓGICOS}

Em relação aos aspectos metodológicos, o presente trabalho fundamenta-se na perspectiva da pesquisa exploratória dentro dos procedimentos metodológicos da investigação qualitativa. No intuito de obter mais conhecimento sobre o objeto de estudo, utiliza-se a pesquisa exploratória que "[...] busca apenas levantar informações sobre um determinado objeto, delimitando assim um campo de trabalho, mapeando as condições de manifestação desse objeto." (SEVERINO, 2017, s. p.). Além disso, por meio da investigação exploratória, "[...] busca-se conhecer com maior profundidade o assunto, de modo a torná-lo mais claro ou construir questões importantes para a condução da pesquisa." (RAUPP; BEUREN, 2006, s. p.). Portanto, visando desenvolver uma listagem dos principais aplicativos de Realidade Aumentada existentes para a aprendizagem de matemática nas plataformas Android, buscou-se proceder uma busca com os seguintes parâmetros:

1. identificar na loja Google Play (https://play.google.com/store/apps?hl=pt-br) aplicativos na categoria "Educação" com foco em matemática e Realidade Aumentada para os dispositivos com sistema Android;

2. realizar buscas por aplicativos em qualquer nacionalidade, ou seja, aplicativos buscar por aplicativos nacionais e internacionais; 
3. enumerar, primeiramente, os aplicativos melhores avaliados contendo informações como: nome, desenvolvedor, sistema operacional compatível, descrição, nota e número de avaliadores;

4. listar os aplicativos com maior quantidade de avaliações dentre os ordenados inicialmente.

Após as etapas identificadas sobre a pesquisa exploratória, realizaram-se as classificações dos aplicativos encontrados conforme as especificações anteriormente descritas. Logo, a seguir, apresentam-se os aplicativos melhores avaliados considerando os procedimentos dos itens 3 e 4.

\section{RESULTADO DO ESTUDO REALIZADO}

Em relação à primeira busca realizada, um quadro foi desenvolvido para organizar os dados encontrados. Porém, pode-se notar que os aplicativos não possuem um número razoável de avaliadores em relação aos seus desempenhos. $O$ Quadro 1 ilustra os detalhes.

Quadro 1: Aplicativos de Realidade Aumentada direcionados para matemática.

\begin{tabular}{|c|c|c|c|c|c|}
\hline Nome & $\begin{array}{l}\text { Desenvo } \\
\text { Ivedor }\end{array}$ & $\begin{array}{c}\text { Sistem } \\
\mathbf{a}\end{array}$ & Descrição & $\begin{array}{c}\text { Not } \\
\text { a }\end{array}$ & $\begin{array}{c}\text { № } \\
\text { avalia } \\
\text { dores }\end{array}$ \\
\hline $\begin{array}{c}\text { Tango } \\
\text { maths AR }\end{array}$ & $\begin{array}{c}\text { Grinteam } \\
\text { LTD }\end{array}$ & $\begin{array}{l}\text { Android } \\
2.3 \text { ou } \\
\text { superior }\end{array}$ & $\begin{array}{l}\text { Tango Maths é um } \\
\text { aplicativo de realidade } \\
\text { aumentada eram os seus } \\
\text { filhos brincar e aprender } \\
\text { multiplicação. }\end{array}$ & 3,5 & 2 \\
\hline FruitPi & $\begin{array}{c}\text { Wuhan } \\
\text { Showbab } \\
\text { ySoftwar } \\
\text { e }\end{array}$ & $\begin{array}{l}\text { Android } \\
4.3 \text { ou } \\
\text { superior }\end{array}$ & $\begin{array}{l}\text { Esta é uma aplicação de } \\
\text { entretenimento com } \\
\text { tecnologia de AR, educação } \\
\text { matemática é atraente, } \\
\text { especialmente. Tiro a fruta } \\
\text { com resposta certa, ele } \\
\text { ajuda a exercer a sua } \\
\text { contagem e capacidade de } \\
\text { resposta, bem como exercer } \\
\text { a sua coordenação corpo. } \\
\text { Melhorar a capacidade } \\
\text { global dos jogadores, uma } \\
\text { grande arma mágica para a } \\
\text { formação do aluno! }\end{array}$ & 5 & 1 \\
\hline
\end{tabular}




\begin{tabular}{|c|c|c|c|c|c|}
\hline & & & $\begin{array}{l}\text { Querendo saber desafiar o } \\
\text { cérebro mais forte, começar } \\
\text { de jogar. }\end{array}$ & & \\
\hline AR Math & $\begin{array}{c}\text { Chin Ho } \\
\mathrm{Ju}\end{array}$ & $\begin{array}{l}\text { Android } \\
4.0 \text { ou } \\
\text { superior }\end{array}$ & $\begin{array}{l}\text { AR Math é um jogo baseado } \\
\text { em realidade aumentada } \\
\text { que propõe algumas } \\
\text { operações algébricas fáceis } \\
\text { integradas em um corredor } \\
\text { sem fim. }\end{array}$ & - & - \\
\hline $\begin{array}{c}\text { Polyhedra } \\
\text { Aumentad } \\
0 \\
\text { Mirage }\end{array}$ & $\begin{array}{c}\text { M. } \\
\text { Chardine }\end{array}$ & $\begin{array}{l}\text { Android } \\
2.2 \text { ou } \\
\text { superior }\end{array}$ & 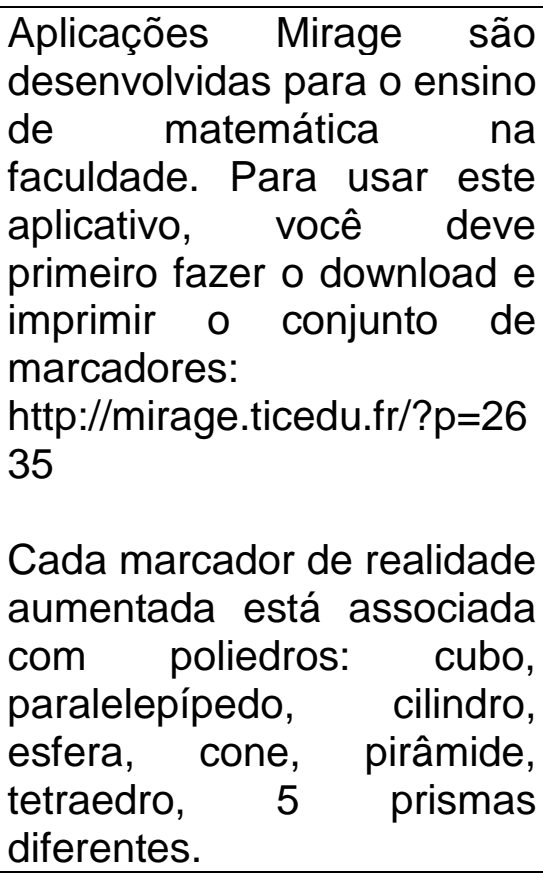 & 4,4 & 50 \\
\hline $\begin{array}{c}\text { Geometri } \\
\text { a } \\
\text { Realidade } \\
\text { Aumentad } \\
\text { a }\end{array}$ & $\begin{array}{c}\text { Mario } \\
\text { Bermude } \\
\quad z\end{array}$ & $\begin{array}{l}\text { Android } \\
4.0 \text { ou } \\
\text { superior }\end{array}$ & $\begin{array}{l}\text { Encontrar uma maneira de } \\
\text { ver a geometria como você } \\
\text { nunca viu. Geometria-AR } \\
\text { realidader aumentada } \\
\text { mostra um grande número } \\
\text { de sólidos, incluindo: } \\
\text { sólidos platônicos famosos. } \\
\text { prismas simples. } \\
\text { uniformes } \\
\text { harmoniosos. }\end{array}$ & 3,7 & 3 \\
\hline $\begin{array}{l}\text { Bimbox } \\
\text { world of } \\
\text { numbers }\end{array}$ & Bimbox & $\begin{array}{l}\text { Android } \\
4.0 \text { ou } \\
\text { superior }\end{array}$ & $\begin{array}{l}\text { BIMBOX mundo dos } \\
\text { números é o jogo familiar e } \\
\text { popular que combina um } \\
\text { aplicativo de Realidade } \\
\text { Aumentada } \\
\text { Lotes de jogos educativos: } \\
\text { Trivia, exercícios de } \\
\text { matemática e informação } \\
\text { interessante! }\end{array}$ & 5 & 1 \\
\hline
\end{tabular}




\begin{tabular}{|c|c|c|c|c|c|}
\hline $\begin{array}{l}\text { What } \\
\text { Is } \\
\text { Geometry }\end{array}$ & Watizeet & $\begin{array}{l}\text { Android } \\
4.1 \text { ou } \\
\text { superior }\end{array}$ & $\begin{array}{l}\text { Um jogo de aprendizagem } \\
\text { incrível onde você encontra } \\
\text { as formas geométricas em } \\
\text { torno de você usando a } \\
\text { câmera do seu telefone. }\end{array}$ & 4.9 & 7 \\
\hline $\begin{array}{c}\text { Interactive } \\
\text { Analytics }\end{array}$ & DES & $\begin{array}{l}\text { Android } \\
2.3 \text { ou } \\
\text { superior }\end{array}$ & $\begin{array}{l}\text { Com esta aplicação, o } \\
\text { aprendizado e compreensão } \\
\text { da área de matemática } \\
\text { tópicos de geometria } \\
\text { analítica está a ser } \\
\text { suportado. Para isto pode } \\
\text { ser ilustrado com a ajuda de } \\
\text { marcadores sobre as } \\
\text { planilhas } \\
\text { imagens de exemplo em um } \\
\text { dispositivo fornecidas, } \\
\text { (smartphone ou tablet). } \\
\text { Para uma introdução ao uso } \\
\text { do aplicativo, por favor, veja } \\
\text { o vídeo aqui fornecidas. }\end{array}$ & 5 & 2 \\
\hline $\begin{array}{l}\text { Geo } \\
\text { RA } \\
\text { Rompe } \\
\text { cabeza } \\
\text { 3D }\end{array}$ & $\begin{array}{c}\text { Openix } \\
\text { Develop }\end{array}$ & $\begin{array}{l}\text { Android } \\
4.0 \text { ou } \\
\text { superior }\end{array}$ & $\begin{array}{l}\text { Recriando conhecimento } \\
\text { matemático. O jogo em } \\
\text { Realidade Aumentada de } \\
\text { armar várias figuras usando } \\
\text { peças tridimensionais. O } \\
\text { objetivo é complementar o } \\
\text { ensino e incluem a } \\
\text { utilização das TIC na sala } \\
\text { de aula. }\end{array}$ & - & - \\
\hline $\begin{array}{c}\text { Arloon } \\
\text { Geometry }\end{array}$ & Arloon & $\begin{array}{l}\text { Android } \\
2.3 \text { ou } \\
\text { superior }\end{array}$ & $\begin{array}{l}\text { Uma maneira fascinante } \\
\text { para descobrir o mundo da } \\
\text { geometria! Este aplicativo } \\
\text { possui modelos 3D com } \\
\text { Realidade Aumentada para } \\
\text { a maioria das formas } \\
\text { geométricas. }\end{array}$ & 4.5 & 22 \\
\hline $\begin{array}{l}\text { Cyber } \\
\text { Chase } \\
\text { Shape } \\
\text { Quest! }\end{array}$ & $\begin{array}{l}\text { PBS } \\
\text { KIDS }\end{array}$ & $\begin{array}{l}\text { Android } \\
2.2 \text { ou } \\
\text { superior }\end{array}$ & $\begin{array}{l}\text { De KIDS PBS e Cyberchase } \\
\text { vem Forma Quest, um } \\
\text { aplicativo cativante, } \\
\text { combinando jogos, quebra- } \\
\text { cabeças e 3D de realidade } \\
\text { aumentada! Forma da } \\
\text { Quest desafia crianças com } \\
\text { idades entre 6-9 de usar } \\
\text { geometria e raciocínio } \\
\text { espacial para aprimorar } \\
\text { suas habilidades para } \\
\text { resolver problemas. }\end{array}$ & 3.7 & 878 \\
\hline
\end{tabular}




\begin{tabular}{|c|c|c|c|c|c|}
\hline $\begin{array}{c}\text { Fig } \\
\text { GeoRA }\end{array}$ & $\begin{array}{c}\text { Pear } \\
\text { \& Apple }\end{array}$ & $\begin{array}{l}\text { Android } \\
4.0 \text { ou } \\
\text { superior }\end{array}$ & $\begin{array}{l}\text { A fim de apoiar o ensino das } \\
\text { disciplinas de figuras } \\
\text { geométricas para alunos do } \\
\text { quinto ano } \\
\text { Esta aplicação permite que } \\
\text { você observe as figuras } \\
\text { geométricas que você sabe } \\
\text { com Realidade Aumentada. }\end{array}$ & 3,5 & 2 \\
\hline $\begin{array}{c}\text { Math } \\
\text { AR }\end{array}$ & $\begin{array}{c}\text { Mark } \\
\text { Somerso } \\
\text { n Aguirre }\end{array}$ & $\begin{array}{l}\text { Android } \\
4.0 \text { ou } \\
\text { superior }\end{array}$ & $\begin{array}{l}\text { Mathar é um aplicativo de } \\
\text { realidade aumentada para } \\
\text { uma operação matemática } \\
\text { simples de ser usado pelos } \\
\text { usuários, especialmente } \\
\text { para as crianças com idade } \\
\text { inferior a } 5-7 \text { anos de } \\
\text { idade ou grau } 1 \text { para o grau } \\
4 \text { estudante com a ajuda de } \\
\text { seus pais. }\end{array}$ & 5 & 1 \\
\hline $\begin{array}{c}\text { O } \\
\text { desenvolv } \\
\text { imento da } \\
\text { aprendiza } \\
\text { gem de } \\
\text { figuras } \\
\text { tridimensi } \\
\text { onais com } \\
\text { realidade } \\
\text { aumentad } \\
\text { a 3D }\end{array}$ & $\begin{array}{c}\text { Matemáti } \\
\text { ca } \\
\text { Inteligent } \\
\text { e }\end{array}$ & $\begin{array}{l}\text { Android } \\
4.0 \text { ou } \\
\text { superior }\end{array}$ & $\begin{array}{l}\text { Vamos criar e ver o } \\
\text { desenvolvimento de várias } \\
\text { formas tridimensionais de } \\
\text { colunas } \\
\text { colunas } \\
\text { retângulos, } \\
\begin{array}{l}\text { pentágonolares, } \\
\text { hexagonais. }\end{array}\end{array}$ & 3,7 & 171 \\
\hline
\end{tabular}

Fonte: Elaborado pelos autores com base na pesquisa realizada na loja virtual do Google.

A partir da ordenação dos aplicativos encontrados na categoria educação na loja virtual do Google direcionados para matemática e RA, selecionou-se os aplicativos com maior quantidade de avaliadores. Percebe-se que somente dois aplicativos possuem comentários em relação às suas funcionalidades ou qualidade das funções inseridas no recurso. Desse modo, os aplicativos foram ordenados pelo número de avaliadores de forma decrescente contendo o ícone, link na Google Play e algumas imagens de exemplo ilustrados no Quadro 2. 
Quadro 2: Aplicativos classificados por quantidade de avaliadores.

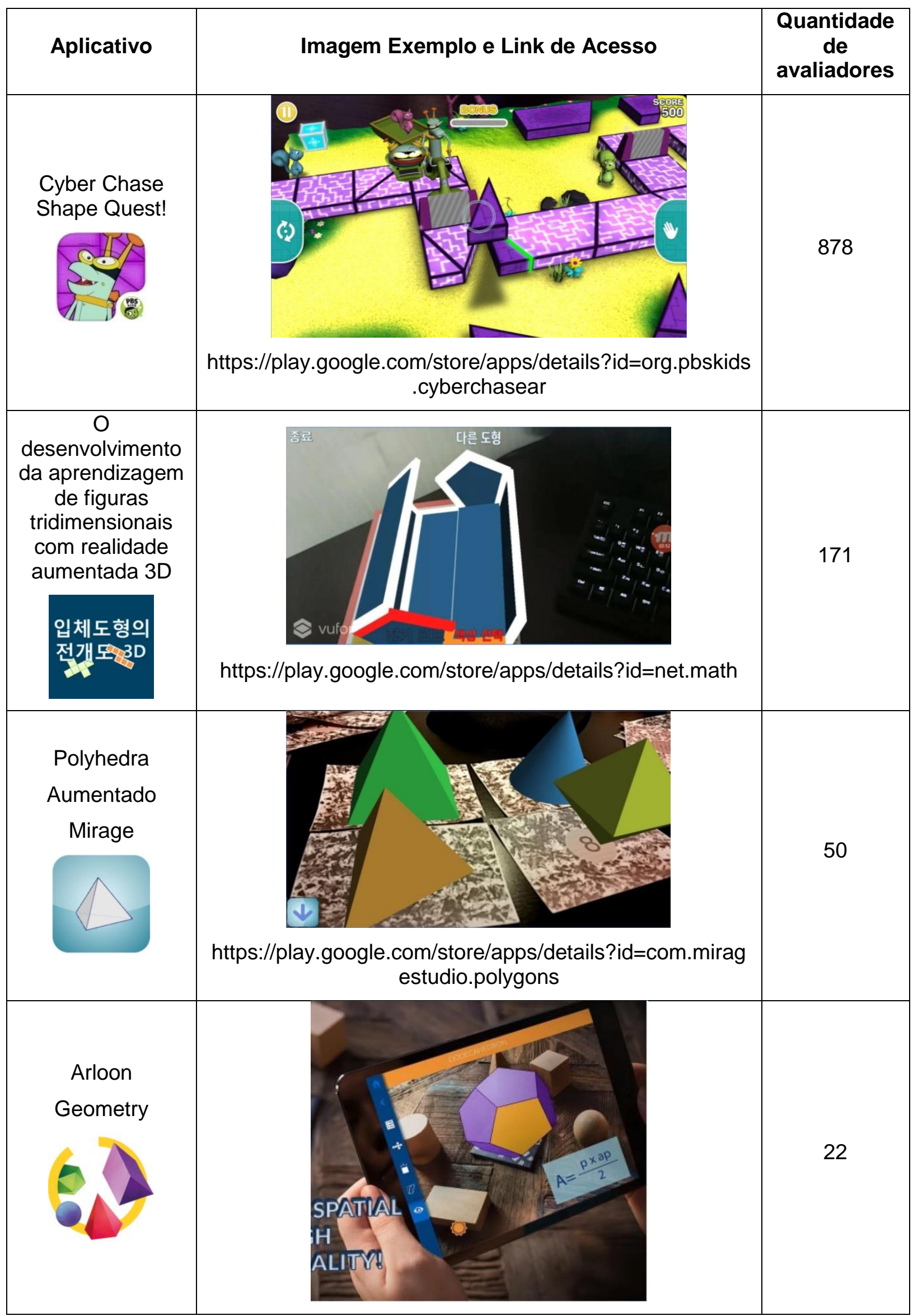




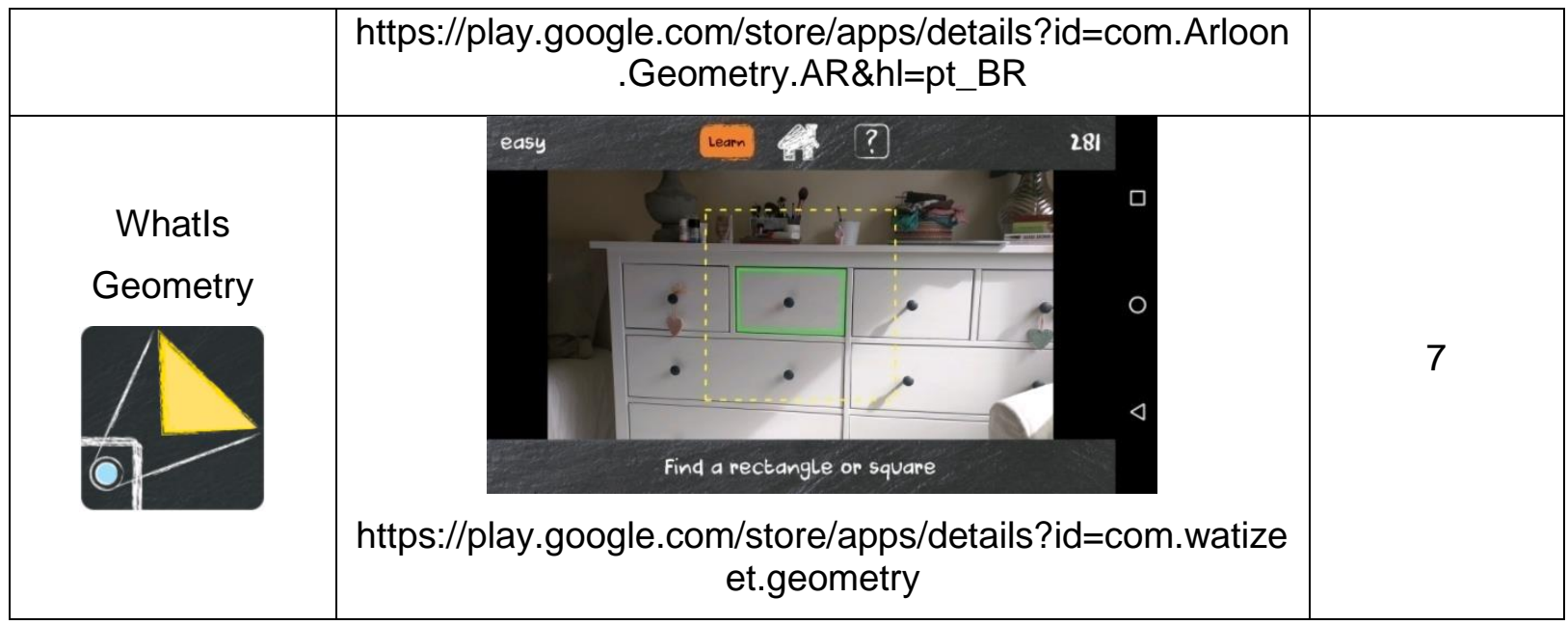

Fonte: Elaborado pelos autores com base na pesquisa realizada na loja virtual do Google.

Em relação ao conteúdo tratado nesses aplicativos melhores avaliados, todos são direcionados à geometria. Entende-se que trabalhar com formas geométricas em 3D, fomentando a percepção espacial dos usuários, pode ter sido um dos motivos para combinar RA e matemática nesse âmbito tecnológico com intenções pedagógicas.

Assim, após as classificações, destacam-se duas aplicações, Cyber Chase Shape Quest e What Is Geometry, que possuem resenhas dos usuários depois de terem feito o download e a utilização desses mesmos aplicativos. Baseado nisso, foi criado um quadro contendo comparações das descrições com a análise dos usuários. Para isso foram lidas todas as resenhas feitas na loja virtual com o intuito de avaliar as funcionalidades, como ilustrado no Quadro 3.

Quadro 3: Quadro com as avaliações dos usuários.

\begin{tabular}{|c|c|c|}
\hline Aplicativo & Descrição & Resenha dos usuários \\
\hline $\begin{array}{l}\text { Cyber Chase } \\
\text { Shape Quest }\end{array}$ & $\begin{array}{c}\text { De KIDS PBS e } \\
\text { Cyberchase vem Forma } \\
\text { Quest, um aplicativo } \\
\text { cativante, combinando } \\
\text { jogos, quebra-cabeças e } \\
\text { 3D de realidade } \\
\text { aumentada! Forma da } \\
\text { Quest desafia crianças } \\
\text { com idades entre 6-9 de } \\
\text { usar geometria e } \\
\text { raciocínio espacial para } \\
\text { aprimorar suas } \\
\text { habilidades para resolver } \\
\text { problemas. }\end{array}$ & $\begin{array}{l}\text { "Muito bom! Recomendo;" } \\
\text { "Adorei O super jogo"; } \\
\text { "Não gostei porcaria"; } \\
\text { "Bom"; } \\
\text { "Um lixo"; } \\
\text { "Divertido"; } \\
\text { "A pelo menos da progasto eu } \\
\text { recomendo só um pouquinho"; } \\
\text { "Uma mentira"; } \\
\text { "Eu dou O estrelas". }\end{array}$ \\
\hline What Is Geometry & $\begin{array}{l}\text { Um jogo de aprendizagem } \\
\text { incrível onde você } \\
\text { encontra as formas }\end{array}$ & $\begin{array}{l}\text { Fantástica maneira de ensinar } \\
\text { geometria aos miúdos! Bom } \\
\text { trabalho!; }\end{array}$ \\
\hline
\end{tabular}




\begin{tabular}{|c|c|l|}
\hline & $\begin{array}{c}\text { geométricas em torno de } \\
\text { você usando a câmera do } \\
\text { seu telefone. }\end{array}$ & $\begin{array}{l}\text { Jogo muito fácil de jogar! As } \\
\text { crianças divertem-se a aprender!; } \\
\text { Muito bom!!!; } \\
\text { Muito pedagógico! }\end{array}$ \\
\hline
\end{tabular}

Fonte: Elaborado pelos autores com base na pesquisa realizada na Play Store.

Verifica-se que a exploração da geometria espacial nos dispositivos móveis é uma forma dos desenvolvedores cativarem os usuários pelas formas geométricas em 3D que se encontram na vida cotidiana. A descrição do aplicativo que diz "[...] encontra as formas geométricas em torno de você usando a câmera do seu telefone [...]." indica que o usuário quando utilizar o aplicativo no seu dispositivo fará uma leitura ao seu redor interpretando as formas regulares por meio da tecnologia. Com freqüência, as pessoas registram "[...] a realidade da vida cotidiana por meio de celulares e câmeras digitais não apenas por uma questão de acesso fácil à tecnologia, mas também em uma tentativa de aproximar o mundo que está ao alcance delas [...]. "(JÚNIOR; SIQUEIRA; ROCHA, 2013, p. 5). Em vista disso, os aplicativos de RA trazem para a realidade mundana uma projeção virtual que interage com usuários sem que os mesmos precisem sair de suas realidades. Isto é, a Realidade Aumentada oferece elementos virtuais que se misturam com o mundo real.

Nessa perspectiva, após a pesquisa exploratória realizada sobre os aplicativos de RA, pode-se perceber que existe a tentativa de aproximar o conteúdo matemático dos estudantes por meio de uma interação visual 3D que é projetada na realidade mundana dos indivíduos. Com isso, proporcionando uma experiência diferente em relação aos livros didáticos e outras práticas educacionais e até mesmo em outros casos propiciando diversão.

\section{CONSIDERAÇÕES FINAIS}

Este artigo pretendeu apresentar um estudo sobre os aplicativos existentes sobre a aprendizagem matemática no campo da RA. A pesquisa realizada sobre os aplicativos de RA que exploram conteúdos matemáticos presentes na loja virtual Google Play, resultou em 14 aplicações melhores avaliadas e com maior número de comentários. Entre elas: cinco aplicativos são voltados para as quatro operações matemáticas elementares direcionados à Educação Infantil (soma, subtração, 
divisão e multiplicação); nove aplicações desenvolvidas para atividades com geometria plana e espacial para diversos níveis de ensino.

Percebeu-se que não existem muitos aplicativos voltados para a Matemática com o intuito de potencializar o conhecimento de conteúdos nem muitos usuários interessados em avaliar e comentar as aplicações. Entende-se que a nota de avaliação na loja virtual possui um número muito baixo de avaliadores. Ou seja, poucas pessoas fizeram download e exploraram os aplicativos. Logo, acredita-se que os desenvolvimentos de aplicações em RA que abordem a matemática não são muito usados nas práticas educacionais.

Portanto, compreende-se que continuar investindo e persistir em criações de aplicativos de RA com o intuito de proporcionar o aumento da produção do conhecimento matemático por meio do virtual misturado com o mundo real é continuar na busca por inovações no âmbito educacional matemático na contribuição de novas práticas com tecnologias.

\section{REFERÊNCIAS}

AZUMA, Ronald T.. A Survey of Augmented Reality. Presence: Teleoperators and Virtual Environments, Massachusetts, v. 6, n. 4, p.355-385, ago. 1997.

BARBOSA, Maria Lúcia Kroeff; ROESLER, Valter; CAZELLA, Sílvio César. Aplicativos móveis para controle da obesidade e modelagem do emagreça saudável. RENOTE, v. 14, n. 1, p.1-10, 2016.

BENTO, Maria Cristina Marcelino; CAVALCANTE, Rafaela dos Santos. Tecnologias Móveis em Educação: o uso do celular na sala de aula. ECCOM, v. 4, n. 7, p. 113-120. jan. 2013.

BERGER, Peter L.; LUCKMANN, Thomas. A construção social da realidade: tratado de sociologia do conhecimento. Petrópolis: Vozes, 2004.

BOALER, Jo. Mentalidades Matemáticas: Estimulando o Potencial dos Estudantes por Meio da Matemática Criativa, das Mensagens Inspiradoras e do Ensino Inovador. Porto Alegre: Editora Penso, 2016.

CONCEIÇÃO, Fábio Henrique Gonçalves; DE MENEZES ALMEIDA, Maria Josefa. Situações-problema como ferramenta metodológica para o ensino de matemática na educação de jovens e adulos. Disponível em:

$<\mathrm{http}$ ://www.fasete.edu.br/revistarios/media/revistas/2015/situacoes_problemas_com o_ferramenta_metodologia_para_o_ensino_de_matematica_na_educacao_de_joven s_e_adultos.pdf>. Acesso em: 01 set. 2017. 
COUTINHO, Gustavo Leuzinger. A Era dos Smartphones: um estudo exploratório sobre o uso dos smartphones no Brasil. 2014. 67 f. TCC (Graduação) - Curso de Comunicação Social, Faculdade de Comunicação, Universidade de Brasília, Brasília, 2014.

CRUZ-CUNHA, Maria Manuela et al. Realidade Aumentada e Ubiquidade na Educação. IEEE-RITA, v. 5, n. 4, p. 167-174, 2010.

DA SILVA, Monielle Gomes; BATISTA, Silvia Cristina Freitas. Metodologia de avaliação: análise da qualidade de aplicativos educacionais para matemática do ensino médio. RENOTE, v. 13, n. 1, 2015.

DE SOUZA, Márcio Vieira; GIGLIO, Kamil (Ed.). Mídias digitais, redes sociais e educação em rede: experiências na pesquisa e extensão universitária. São Paulo: Editora Blucher, 2015.

FORTE, Cleberson. Eugenio. Software Educacional Potencializado com Realidade Aumentada para uso em Física e Matemática. 2009. 200 f. Dissertação (Mestrado) - Curso de Ciências da Computação, Faculdade de Ciências Exatas e da Natureza, Universidade Metodista de Piracicaba, Piracicaba-SP, 2009.

CUPERSCHMID, Ana Regina M.; FREITAS, Marcia. Regina de. Possibilidades de Uso de Realidade Aumentada Móvel para AEC. In: SIMPÓSIO BRASILEIRO DE QUALIDADE DO PROJETO NO AMBIENTE CONSTRUÍDO, v. 3; ENCONTRO DE TECNOLOGIA DE INFORMAÇÃO E COMUNICAÇÃO NA CONSTRUÇÃO, 5. Campinas, SP. Anais... Campinas, 2013.

JÚNIOR, Alfredo Eurico Vizeu Pereira; SIQUEIRA, Fabiana Cardoso de; ROCHA, Heitor Costa Lima da. A Influência do Telejornalismo na Construção Social da Realidade: O Poder da Mídia na Definição da Realidade e a Contribuição da Coprodução. In: CONGRESSO BRASILEIRO DE CIÊNCIAS DA COMUNICAÇÃO, 35. Manaus-AM, Anais... Manaus, 2013.

KIRNER, Claudio; SISCOUTTO, Robson. Fundamentos de Realidade Virtual e Aumentada. In: IX SYMPOSIUM ON VIRTUAL AND AUGMENTED REALITY, 2007, PetrópolisRJ. Realidade Virtual e Aumentada: conceito, projetos e aplicações. [s.i.]: SBC, 2007. p. 2 - 21.

MELGAÇO, Paula; DIAS, Vanina Costa; SOUZA, Juliana M. P. de; MOREIRA, Jacqueline de O. Como a tecnologia muda o meu mundo: imagens da juventude na era digital. Curitiba: Appris, 2017.

PORTANOVA, Ruth. Um currículo de matemática em movimento. Porto Alegre: EDIPUCRS, 2005.

RAUPP, F.M.; BEUREN, I.M. Metodologia da pesquisa aplicável às ciências sociais. In. BEUREN, I.M. (Org.). Como elaborar trabalhos monográficos em contabilidade: teoria e prática. 3.ed. São Paulo: Atlas, 2006. Cap.3, p.76-97.

RODRIGUES, Elsa Margarida. Ecos do mundo zero: guia de interpretação de futuros aliens e ciborgues. Coimbra: Press, 2012.

SACCOL, A.; SCHLEMMER, E.; BARBOSA, J. M-learning e u-learning: novas perspectivas das aprendizagens móvel e ubíqua. São Paulo: Prentice Hall, 2011. 
Estudo exploratório sobre aplicativos de realidade aumentada direcionados para a aprendizagem Matemática

SENGE, Peter; JAWORSKI, Joseph; SCHARMER, C. Otto; FLOWERS; Betty

Sue. Presença: propósito humano e o campo do futuro. São Paulo: Editora Cultrix, 2004.

SEVERINO, Antônio Joaquim. Metodologia do trabalho científico. São Paulo, Cortez editora, 2017.

SCHOR, Tatiana. Ciência e tecnologia: o caso do Experimento de Grande Escala da Biosfera-Atmosfera na Amazônia (LBA). São Paulo: Annablume, 2008. 